\title{
Prácticas estéticas antirracistas en México desde una perspectiva crítica de género: la obra de Petrona de la Cruz
}

Amarilis Pérez Vera ${ }^{1}$

\section{Resumen}

Este artículo es sobre prácticas estéticas performativas antirracistas en México, una línea de investigación que desarrollé en la tesis de doctorado, la cual además contempló tales prácticas en la comunidad chicana de California, Estados Unidos. En esta oportunidad, se reflexionará sobre cómo las prácticas estéticas performativas desarrollan un conocimiento encarnado y una praxis teórico-metodológica para confrontar la violencia de género en relación con las especificidades de los racismos en México, restaurándose así la agencia de las personas o grupos de personas afectadas. Con este propósito analizaremos la performance escénic: Dulces y Amargos Sueños de Petrona de la Cruz Cruz. Así se formularán cuestionamientos a la ideología del mestizaje y al lugar que tal ideología configura, específicamente, para las mujeres indígenas en la nación mexicana. De la Cruz Cruz negocia entre la identidad nacional mestiza y la propia, posicionándose desde una crítica con perspectiva de género a la experiencia personal como mujer indígena. El estudio de esta performance escénica premitirá hacer disímiles consideraciones sobre cómo se entretejen la violencia de género y el racismo en México; y también conocer los diversos modos en que los propios cuerpos racializados negativamente se constituyen en actores de la representación y en sujetos políticos interviniendo sobre la historia, la realidad social y la propia realidad estética y poética mediante la reconfiguración tanto de los cuerpos representados como de los temas, las lenguas, los materiales, los ritmos, los colores, las perspectivas ideológicas y teóricas. Para llevar a cabo esta investigación se hizo trabajo de archivo y de campo. Las principales fuentes fueron las reflexiones académicas, especialmente de corte histórico, sobre racismo, mestizaje y arte en México; así como la experiencia directa de múltiples visualizaciones de la performance y la revisión documental del mismo.

\section{Palabras clave}

Arte. Antirracismo. México.

\footnotetext{
${ }^{1}$ Doutora em Estudos Latinoamericanos na Universidad Nacional Autónoma de México. E-mail: teresaoccidental@gmail.com.
} 


\section{Resumo}

Este artigo trata das práticas estéticas performativas anti-racistas no México, linha de pesquisa que desenvolvi em minha tese de doutorado, que também contemplou práticas semelhantes na comunidade chicana da Califórnia, Estados Unidos. Nesta ocasião, refletirá sobre como as práticas estéticas performáticas desenvolvem um conhecimento corporificado e uma práxis teóricometodológica para enfrentar a violência de gênero em relação às especificidades do racismo no México, restaurando assim a agência das mulheres como indivíduos e como membros de coletivos e comunidades. Para tanto, analisaremos a performance: Dulces y Amargos Sueños de Petrona de la Cruz Cruz. Assim, vai-se questionar à ideologia da miscigenação e ao lugar que tal ideologia configura para as mulheres indígenas na nação mexicana. De la Cruz Cruz negocia entre a identidade nacional mestiça e a sua própria, posicionando-se desde uma crítica com perspectiva de gênero até a experiência pessoal como mulher indígena. 0 estudo desta performance nos permite fazer considerações diferentes sobre como a violência de gênero e o racismo estão entrelaçados no México; e também conhecer as diversas formas pelas quais os próprios corpos negativamente racializados se tornam atores de representação e sujeitos políticos, intervindo na história, na realidade social e na própria realidade estética e poética através da reconfiguração tanto dos corpos representados como dos temas, linguagens, materiais, ritmos, cores, perspectivas ideológicas e teóricas. 0 trabalho de arquivo e de campo foi realizado para levar a cabo esta investigação. As principais fontes foram reflexões acadêmicas, especialmente de caráter histórico, sobre racismo, miscigenação e arte no México; bem como a experiência direta da performance e a revisão documental da mesma.

\section{Palavras-chave}

Arte. Antirracismo. México.

\section{Abstract}

This paper is about anti-racist performative aesthetic practices in Mexico, a line of research that I developed in my doctoral dissertation, which also was about such practices in the Chicano community of California, United States. For now, we will be thinking on how performative aesthetic practices (re)produce a theoretical-methodological praxis based on an embodied knowledge that confronts the gender violence related to the specificities of racism in Mexico. In the process, the agency of individuals or groups of people, who suffer because of racism, is restored. For this purpose, we will analyze the performance: Dulces y Amargos Sueños by Petrona de la Cruz Cruz. This analysis allows us to formulate questions about the ideology of miscegenation and concerning indigenous women in the Mexican nation. De la Cruz Cruz negotiates between the mestizo national identity and her own identities, positioning herself from her personal experiences as indigenous woman. In the end, one can be aware of how gender violence and racism are intertwined in Mexico. 
The artist intervenes in the social, aesthetic, and poetic reality itself, introducing new forms of self-representation through her interests, language, materials, rhythms, colors, ideological and theoretical perspectives. I used two research strategies: archival and fieldwork. Data have been collected from academic papers about racism, miscegenation, and art; as well as from the live experience of performance and its documentary review.

\section{Keywords}

Art. Anti-racism. Mexico.

\section{Introducción}

En los últimos 20 años ha aumentado considerablemente el número de investigaciones sobre racismo en México. En su mayoría, tales estudios provienen de estos campos disciplinares: la antropología, la historia, la sociología y, más recientemente, los estudios interculturales. Éstos se han enfocado, principalmente, en las poblaciones indígenas, afromexicanas, migrantes y su acceso a los derechos humanos y civiles, entre ellos, la salud, la educación y la justicia. Pero sobre todo, se ha instrumentado una crítica a la ideología étnico-racial dominante del Estado nación mexicano: el mestizaje. Sin embargo, por una parte, son pocos y aislados los estudios dedicados a arte y racismo y/o antirracismo; y, por otra, varias investigadoras (GALL, MORENO 2016, RUIZ 2001) han señalado la necesidad de estudiar la problemática del racismo desde un enfoque interseccional. Por tanto, en este artículo se abordará el tema del racismo y el arte en México poniendo en cuestión la ideología del mestizaje desde una perspectiva crítica de género de la performance escénica Dulces y Amargos Sueños de Petrona de la Cruz Cruz. La pregunta que guiará esta reflexión es ¿qué conocimiento podrían estar produciendo las prácticas estéticas sobre las formas en que se expresa, se vive y se confronta el racismo en México? Para darle respuesta, se introducirá el estado de la cuestión del racismo en México y se recurrirá al aparato teórico y metodológico de los Estudios de Performance para articular el análisis y la reflexión. Este artículo afirmará que los propios cuerpos racializados negativamente, constituidos en actores de la representación y en sujetos políticos mediante las prácticas estéticas performativas, (re)producen un conocimiento encarnado y una praxis teórico-metodológica para enfrentar la violencia de género en relación con las especificidades del racismo en México. 


\section{Racismo, mestizaje y género en México}

El enriquecimiento en el número y la diversidad de los estudios sobre racismo en México se debe, fundamentalmente, a la denuncia que el Ejército Zapatista de Liberación Nacional (EZLN) hizo contra el Estado-nación mexicano, llamándolo racista durante el alzamiento armado en 1994; y a la participación de México en la Conferencia Mundial contra el Racismo, la Discriminación Racial, la Xenofobia y las Formas Conexas de Intolerancia, a raíz de cuyas declaraciones y acuerdos se promulgó la Ley Federal para Prevenir la Discriminación y se creó el Consejo Nacional para Prevenir la Discriminación (CONAPRED) en 2003. Posteriormente se puede percibir un incremento continúo en el conocimiento y reconocimiento público sobre cómo, desde diversos ámbitos de la sociedad civil, se denuncia y combate el racismo en México. Específicamente desde la academia, investigadores e investigadoras (CASTELLANOS, 2000a, 2000b; GALL, 2001, 2004; LÓPEZ BELTRÁN, 2001, 2014; WADE, 2005; OEHMICHEN, 2006; SEGATO, 2010; RIVERA CUSICANQUI, 2010, 2015; GÓMEZ IZQUIERDO Y SÁNCHEZ DÍAZ DE RIVERA, 2012; VELÁZQUEZ, 2016; MORENO, 2016) han señalado que mediante el proyecto civilizatorio e ideológico del mestizaje se ha configurado un racismo antiindio y antiafrodescendiente velado precisamente por el argumento de que no puede ser racista un país que exalta la mezcla de "sangres y culturas". Tales discursos han operado ocultando la existencia del racismo como principio estructurante de la vida social e institucional en México. Un país donde, según una encuesta realizada en 2010, aproximadamente el $64.6 \%$ de la población se considera morena y el $40 \%$ está total o parcialmente de acuerdo con que se les trata de forma desigual por su tono de piel (CONSEJO NACIONAL PARA PREVENIR LA DISCRIMINACIÓN, 2011).

Se entiende que la ideología mestizante ha promovido la asimilación y el blanqueamiento de la población en términos bioculturales, ha fomentado el desprecio y la autodenigración de la mayoría de la población; ha restringido a determinados grupos humanos el acceso a los bienes materiales y simbólicos de la nación, y también ha desarticulado, por años, la movilización política, social y académica en torno al problema del racismo.

Si bien el racismo en México es anticonstitucional y, por otra parte, la ideología mestizante no dicta explícitamente el segregacionismo ni el genocidio, las formas conocidas más extremas del racismo; la realidad es que, en un contexto de violencia e impunidad exacerbadas, el racismo opera 
agravando la situación de vulnerabilidad de diversos grupos humanos, especialmente indígenas, afrodescendientes y migrantes en tránsito.

Gómez Izquierdo y Sánchez Díaz de Rivera (2012) plantean que la mestizofilia - el amor por la idea de que nuestro país es mestizo (BASAVE, 2002) - es una corriente del pensamiento de las élites intelectuales, políticas, científicas y de los grupos dominantes mexicanos liberales del siglo XIX, que se formuló como vía de homogeneización cultural, racial, lingüística, de patrones de producción y consumo de la población mexicana, cuya "diversidad racial y étnica" constituía, para los principales ideólogos de estas élites, una amenaza para el progreso y la modernización de la nación independiente.

Gall (2013) profundiza en esta cuestión y afirma que los líderes independistas dieron los primeros pasos en el proyecto mestizófilo al momento de concebir la nueva nación. Imaginaron que era posible abolir las castas heredadas del periodo colonial y borrar las diferencias raciales que, sin embargo, sobreviven hasta el presente. Uno de los principales promotores de este proyecto, apunta Gall (2013), fue el liberal José María Luis Mora (17941850), quien consideraba que la "amenaza roja" debía "disolverse" mediante el mestizaje; no hizo ninguna mención a la población afrodescendiente; y manifestó explícitamente la importancia de la inmigración europea para "blanquear la raza" e "impulsar el desarrollo industrial del país" (GALL, 2013, p. 4).

Hoy se reconoce al filósofo mexicano José Vasconcelos, Secretario de Instrucción Pública de México (1920-1924) y Rector de la Universidad Nacional (1920), como el principal ideólogo de la "raza cósmica" en México, concebida por él como una fusión idealizada y contradictoria entre todas las razas, de la que debía surgir una "quinta raza" cuyo "papel cósmico" sería importante. Sin embargo, plantea Gall (2013) fue el antropólogo Manuel Gamio quien, sin polemizar con esta creación vasconceliana, desarrolló el proyecto mestizante del Estado mexicano posrevolucionario, al afirmar que la real esperanza de desarrollo para pueblos indígenas en este país era mestizarse, a pesar de que reconocía en ellos el verdadero origen de la nación mexicana (BONFIL, 1987, p. 24 en GALL,2013. p. 289). Así se instrumentó amalgamar al cuerpo de nación mestiza la diversidad de los pueblos indígenas.

Por una parte, las políticas indigenistas mestizantes - puestas en marcha como estrategias de integración económica, política y social mediante la acción del Instituto Nacional Indigenista (INI) (1948-2003) - significaron la intención de mejorar el acceso a la educación, la salud y la vivienda para las personas mexicanas que se integraran al modelo racial y étnico del mestizaje; pero, por 
otra parte, significaron la desaparición progresiva de las culturas y lenguas indígenas y la represión contra quienes se oponían a este ideal e insistieron en mantener su identidad diferenciada, como los pueblos yaqui, maya, otomí y cora.

Igualmente, el mestizaje mexicano negó la existencia de afrodescendientes; quienes, se calcula, eran el tercer grupo poblacional más importante del país en 1810 (AGUIRRE BELTRÁN, 1989). A principios del siglo XX, se les consideró inasimilables por ser "racialmente inferiores", "incompetentes ocupacionalmente", "incapaces de convertirse en verdaderos ciudadanos" y “peligrosos para la población indígena nacional"(SAADE, 2010, pp. 137-238 en GALL, 2013, p. 294). Y a lo largo de este mismo siglo se consolidó la minimización y la ignorancia sobre sus aportes económicos y culturales. No fue sino hasta 2015 que el Estado mexicano reconoció a esta población mediante la inclusión de la categoría afrodescendiente en la pregunta de autoidentificación en la Encuesta Intercensal realizada por el INEGI; y en 2019 la reconoció constitucionalmente mediante la adición del apartado $\mathrm{C}$ al artículo dos de la Carta Magna. Apartado en el que se declara que los pueblos y comunidades afromexicanas son parte de la nación pluricultural mexicana y, por tanto, tienen derecho a la libre determinación, autonomía, desarrollo e inclusión social. Lamentablemente, en la práctica, estos derechos no se ejercen; aunque en las elecciones del 6 de junio de 2021 por primera vez los afromexicanos y las afromexicanas ocuparon un lugar en la Cámara de Diputados por acción afirmativa, medida implementada por el Instituto Nacional Electoral (INE) con el objetivo de reconocer la participación política de grupos históricamente discriminados y vulnerados, entre ellos, los indígenas, las mujeres y las personas con discapacidad y de la comunidad LGBTTTIQ+ (INE, 2021).

Efectivamente, mediante la ideología y el proyecto político-cultural del mestizaje se ha definido la identidad nacional mexicana y el lugar que en ella ocupan los cuerpos mestizos, blancos, indígenas, afrodescendientes, extranjeros y morenos; pero también se trazó cuál sería el desempeño de las mujeres en esta intrincada definición étnico-racial y cultural del ser mexicano.

Siguiendo a Apen Ruiz (2001) podemos afirmar que en el imaginario nacional posrevolucionario la mujer mexicana ha sido representada mediante los símbolos de la Malinche y la Virgen de Guadalupe, quienes encarnan respectivamente la mujer/madre indígena ultrajada y traidora, y la mujer/madre morena virgen, amorosa y protectora de los indios. Se han construido ideales sobre género, raza, cultura y nación empleando estas figuras femeninas. 
Plantea Ruiz (2001) que en México las mujeres han sido sistemáticamente infantilizadas. Por tanto, se les ha excluido del ámbito educacional y profesional. En el imaginario colectivo hay una preferencia hacia aquellas que sean puras, generosas e incapacitadas para ejercer la política. La autora cita a Manuel Gamio diciendo: "nuestras mujeres indígenas no saben leer ni escribir pero conservan más intensa y fielmente que los hombres una gran herencia de hábitos, tendencias y educación" (RUIZ, 2001, p. 152). Efectivamente, la mestiza - o en otras palabras, la "indígena moderna" - representa la salvaguarda y el agente transmisor de las tradiciones, la cultura auténtica y originaria, porque ella, a diferencia de la mujer blanca, no era es feminista ni había abandonado aún su naturaleza: cuidar a su esposo y a sus hijos.

Este imaginario sobre la mujer se materializa en la realidad social. En México, la desocupación laboral de las mujeres indígenas y rurales, así como las tasas de analfabetismo son cuatro veces mayor que la de los hombres; y son ellas quienes dedican 44 horas a la semana al trabajo doméstico mientras ellos solo una cuarta parte de este tiempo, quienes por el contrario, emplean tres veces más tiempo en la participación de actividades públicas (ORTEGA PONCE, 2012). Asimismo, esta visión sobre la mujer indígena se reproduce en la realidad estética y discursiva de la nación. Es apabullante en los medios audiovisuales de difusión o artísticos, la imagen de la mujer indígena como empleada doméstica. Pareciera que ninguna otra cosa aconteciera en la vida de estas mujeres. Durante el 17 Festival Internacional de Cine de Morelia, las cineastas purépecha Magda Cacari, tzotziles María Sojob y Dolores Sántis Gómez, y mixtecas Ángeles Cruz y Yolanda Cruz expresaron que no se sienten representadas en los papeles predominantemente destinados a las actrices indígenas en América Latina, ya no sólo en México. Un hecho que ellas consideran abiertamente racista, y un motivo por el cual han decidido dirigir y escribir sus propias historias (CHARBELL, 2019).

Estas mujeres cineastas están produciendo su obra en un contexto marcado por la conciencia política en torno de esta realidad. En los últimos 30 años, acontecimientos que han cimbrado la vida nacional, como los feminicidios en Ciudad Juárez (1993), la existencia del EZLN, la llamada "guerra contra el narcotráfico" (2006-2012) y la nueva ola del Feminismo en América Latina, han redundado en una capacidad organizativa por parte de las mujeres que luchan por que no se les mate ni a ellas ni a sus seres queridos, que se organizan y buscan por todo el país a las más de 140 mil personas desaparecidas, ${ }^{2}$ y

2 Según datos de la Secretaría de Gobernación, desde los años sesenta del siglo XX hasta 2019, en México han desaparecido 147033 personas, de las cuales han sido localizadas 85 396. El 97.43\% de 
defienden el derecho a la tierra, la educación, la salud y la reproducción elegida, entre muchas otras demandas para que se les reconozca plenamente como ciudadanas.

Por tanto, es posible y necesario elaborar una crítica a la ideología del mestizaje desde una perspectiva de género. Este artículo está centrado en este aspecto que se desarrollará mediante el análisis de la performance escénica Dulces y Amargos Sueños de Petrona de la Cruz Cruz.

El principal enfoque metodológico empleado está ligado a los Estudios de Performance, un campo interdisciplinario estrecha y principalmente vinculado a los estudios teatrales, lingüísticos y antropológicos, dedicado a analizar una diversidad de eventos culturales (performances) en la medida en que éstos, por mediación de los cuerpos, (re)actualizan - conservando o modificando - la realidad social y simbólica. A pesar de los orígenes literarios y lingüísticos de la categoría performance, los Estudios de Performance vienen a ser una respuesta a la tradición logocéntrica de la reproducción del conocimiento, haciendo énfasis en la experiencia viva, los cuerpos, los espacios de (re)presentación y los procesos de creación en un sentido amplio. Para este artículo, posicionarse desde este campo disciplinar facilitó la elaboración de preguntas específicas sobre la racialización de los cuerpos así como sobre la agencia y los actores que intervienen en la realidad social.

Para esta investigación se recurrió a variados métodos cualitativos de recolección de datos, en correspondencia con la pregunta de investigación y los objetivos planteados en la introducción, pero también determinados por dificultades afrontadas en el proceso: primero, la performance es efímera y aunque se repite, nunca es idéntica a sí misma; segundo, en México, como ya se mencionó, escasea la literatura respecto del tema racismo y arte, y se elude el uso de la palabra clave racismo y/o antirracismo para catalogar y archivar documentos que registran las prácticas estéticas performativas. Para sortear esta última dificultad, se realizó un movimiento del archivo - evidencias en forma de objetos resistentes hasta cierto punto al deterioro material(TAYLOR, 2003) al repertorio, memoria encarnada en actos "efímeros" (TAYLOR, 2003). Este último revelaba todo aquello que mediante la opresión, la violencia y el terror - tecnologías éstas del poder-saber hegemónico - se elimina de los archivos de la nación: textos, documentos, edificios, incluso huesos, entre otros materiales (TAYLOR, 2003, p. 19).

estas personas desapareció a partir de 2006, cuando el expresidente Felipe Calderón inició a la llamada "guerra contra el narcotráfico" (SECRETARÍA DE GOBERNACIÓN, 2020, p. 18-20). 
Por tanto, se asistió a la presentación de la performance Dulces y Amargos Sueños $\mathrm{y}$, además, se consultaron materiales que han documentado presentaciones de la misma en diferentes espacios, como fotografías, programas de mano, artículos en la prensa o académicos y, además, se sostuvo un diálogo con la creadora. Esta diversidad de recursos permitió considerar la realidad viva, la mediación discursiva así como el escenario político y social en el que se ha presentado la performance. Por tanto, esta investigación se nutrió de los datos recabados durante la revisión documental y la experiencia viva y directa de la performance. La recolección de datos estuvo dirigida por la intención de hacer énfasis en las nociones de espacio, materiales, manierismos, cuerpo, racismo, mestizaje y género; $\mathrm{y}$, también, en las percepciones, los sentimientos y las emociones. Este trabajo se enriqueció con el trabajo de campo que se hizo en San Cristóbal de las Casas, Chiapas, en 2018 y 2019.

\section{Violencia de género y racismo en Dulces y Amargos Sueños de Petrona de la Cruz Cruz}

Petrona de la Cruz Cruz nació en Zinacantán, Chiapas, el 23 de septiembre de 1965. La vida de la actriz, escritora y directora de teatro de origen tzotzil estuvo marcada en su niñez y juventud por episodios de discriminación, humillación y violencia psicológica, económica, racial y de género. Sin embargo, mediante la creación artística y literaria, el teatro y la pedagogía, Petrona transfiguró esta experiencia. Para quienes la veían en escena en la comunidad, Petrona era una prostituta, una loca o una exhibicionista, pero ella había encontrado lo que llamaba un camino para sanar (VIVANCO, 2014). Esta experiencia es la que Petrona transmitió a mujeres mayas de diversos orígenes étnicos en la asociación civil Fortaleza de la Mujer Maya (FOMMA) en San Cristóbal de las Casas, Chiapas, asociación que fundó junto a su compañera maya de origen tzeltal, Isabel Juárez Espinoza, con quien hizo una obra itinerante en 1993 para recaudar fondos.

El FOMMA ha sido un espacio de sanación por más de dos décadas (VIVANCO, 2014). Allí las mujeres mayas, jóvenes, adultas, niños y niñas han adquirido herramientas profesionales, legales y psicológicas para hacer frente a la violencia y discriminación. Especialmente para ellas, el FOMMA también es un lugar para pensar y expresar conflictos personales y de la comunidad que no pueden ser manifestados ni en el espacio doméstico/privado/íntimo ni en el público, incluyendo el teatro mismo, todos espacios dominados por los 
hombres, principalmente. Además de tratar la violencia de género, otras problemáticas que atiende el FOMMA son la migración, el desplazamiento forzado, la alfabetización, la educación en tzeltal y tzotzil, la salud mental y físic y los derechos sexuales. Asimismo, en el FOMMA se creó el primer Centro Hemisférico en América Latina en colaboración con el Instituto Hemisférico de Performance y Política para promover las performances artísticas producidas por indígenas de diversos orígenes étnicos en esta región.

Con el tiempo, el trabajo de Petrona y sus compañeras ha sido reconocido dentro y fuera de la comunidad. En 1992, De la Cruz Cruz recibió el Premio Rosario Castellanos en Literatura, en 2002 fue becaria del Consejo Nacional para la Cultura y las Artes (CONACULTA) y en 2019 el Congreso del Estado de Chiapas le otorgó la Medalla Rosario Castellanos por su creación literaria y teatral en favor de los derechos de los pueblos indígenas, las mujeres y los niños y las niñas. El FOMMA recibió en 1999 el premio nacional otorgado por el Instituto Mexicano de Investigación de Familia y Población (IMIFAP). Actualmente, De la Cruz Cruz se mantiene activa en su quehacer artístico y pedagógico de manera individual desempeñándose como educadora y teatrista en su región natal, México y el mundo.

Petrona comenzó a hacer teatro casualmente al colaborar en 1990 con la Fundación Mexicana para la Planificación Familiar (Mexfam) en El Burro y la Mariposa y Cuando Menos Burros, Más Elotes; dos obras que fueron representadas en varias comunidades indígenas de la región como parte de un programa de educación sexual. Lo que parecía para Petrona una locura y se hacía por necesidad económica se volvió su profesión. En este periodo, Petrona se formalizó como miembro de Sna Jtz'ibajom, Cultura de los Indios Mayas, A.C. (en tzotzil, La Casa del Escritor), trabajando con Francisco Álvarez y Ralph Lee; y posteriormente ella se formó también en teatro de títeres, expresión corporal, radioproducción cultural y literatura dramática.

En 1995, Petrona publicó el libro para niños Yo Soy Tzotzil (México, DF.: Libros del Rincón, SEP). Su obra "Una Mujer Desesperada” fue traducida al inglés y publicada en la antología Holy Terrors: Latin American Women Perform (Duke University Press, 2003) y "Madre Olvidada" se encuentra en La Risa Olvidada de la Madre. Diez Años de la Fortaleza de la Mujer Maya (Ediciones La Burbuja, 2005). Otras de sus obras son: Infierno y Esperanza, Desprecio Paternal, La Monja Bruja, Soledad y Esperanza, y La Tragedia de Juanita; las cuales están dedicadas a todas las mujeres, quienes dan vida y, sin embargo, se les quita la vida; y a todas las mujeres que por ser indígenas se les tilda de ignorantes, en palabras de Petrona (ARISTEGUI, 2019). 
En su mayoría, estas obras representan, en un ambiente doméstico y rural de los Altos de Chiapas, cómo las mujeres de las comunidades indígenas, en detrimento de su bienestar económico y profesional, son condenadas a las labores domésticas en sus comunidades o en casa de "mestizas" en las principales ciudades San Cristóbal y Tuxtla; así como sujetas al sufrimiento provocado, desde la niñez, por una diversidad de abusos físicos, económicos y psicológicos a manos de los hombres que las rodean, no importa si son hijos ya adultos, hermanos, padres, tíos o vecinos dentro y fuera del hogar. Las historias de vida representadas mediante estas obras están basadas en hechos autobiográficos, las memorias y las huellas emocionales y de lucha de Petrona y sus compañeras en el FOMMA.

Para De la Cruz Cruz (2011), performance es el quehacer que ella emprende desde su propio cuerpo y cosmovisión para trabajar un problema. Esto es diferente al teatro porque este último se basa en un documento escrito previamente. En la performance, nos dice Petrona, a diferencia del teatro, una "desentierra" una historia del pasado y para representarla puede encarnar a un hombre que dirá lo que "el macho" no puede decir en la vida real: hablar y poner nombre a toda la violencia machista que ejerce.

De la Cruz Cruz (2011) explica cómo, para representar una experiencia que no conoce, debe transformarse a sí misma, su cuerpo, su pensamiento y su cosmovisión. Para crear tales representaciones, Reflejo de la Diosa Luna, grupo de teatro del FOMMA compuesto sólo por mujeres, recurre a las máscaras como entrenamiento y como tradición. Sin embargo, en este sentido, nos comenta De la Cruz Cruz (2011), el cambio está en la vida misma, en la transformación de todas ellas como mujeres mayas al hacer arte.

Mediante el trabajo actoral, dramatúrgico y pedagógico Petrona y sus compañeras del FOMMA, provenientes de diversas comunidades mayas, cuestionan el desempeño de ellas como mujeres en la cotidianidad y la historia de la comunidad más allá del esquema de dominación-obediencia. Para De la Cruz Cruz (2011), mediante el arte, las mujeres no sólo crean un producto estético como una obra teatral, un mural, una pintura, sino que elaboran otras formas de vivir diferentes $y$, por tanto, se transforman a sí mismas paso a paso.

Como se mencionó anteriormente, una de las dificultades más grandes enfrentadas durante esta investigación fue el modo en que se resguarda la información en los catálogos de las bibliotecas mexicanas. Aunque Petrona de la Cruz Cruz ha sido galardonada y reconocida por su quehacer literario, teatral y pedagógico en México, son pocos los artículos académicos que se han escrito sobre su prolija producción. 
A esta escasez de información, hay que agregar que si bien Petrona ha escrito varios artículos, en su mayoría permanecen inéditos, lo que entorpece el acceso al pensamiento crítico de la autora. Estos textos son: "El Teatro y los Problemas de las Mujeres de Los Altos de Chiapas"; "Importancia de la Educación para la Mujer Indígena"; y "Carencias Culturales y Educativas en Chiapas". Además, si bien el tema que fundamentalmente atraviesa la obra de Petrona es el género, tanto su labor, su creación como sus discursos orales y escritos, señalan la importancia, el valor y el derecho a la vida de los diversos grupos étnicos. Sin embargo, su obra no es abiertamente reconocida como antirracista.

No obstante, existe una decena de textos que se refieren específicamente a la obra de Petrona de la Cruz Cruz y a su localización en un contexto de literatura y teatro maya contemporáneo. A continuación se hará referencia a los aspectos destacados de estos documentos en aquellos elementos de interés para este artículo.

En general, los estudios han señalado principalmente la perspectiva de género que sostienen Petrona y sus compañeras del FOMMA como mujeres indígenas pertenecientes a diversos grupos étnicos mayas de Chiapas. Los investigadores y las investigadoras hacen especial énfasis en el poder transformador que para estas mujeres tiene el teatro y la performance tanto en el ámbito individual, íntimo como en el comunitario. Esta transformación surge del trabajo con la memoria y el cuerpo de cada una de ellas en los entrenamientos actorales durante la creación colectiva. Mediante el trabajo con el cuerpo se recrea la confianza y se accede a la memoria y a una corporalidad que difiere de la performatividad del género y la etnia que se les asigna a las mujeres indígenas por los "usos y costumbres" y por el imaginario nacional que, mediante la ideología del mestizaje, ha promovido la negación de las identidades indígenas contemporáneas en las agendas políticas, los planes de desarrollo y los programas educativos.

Algunas de estas heridas han sido tan profundamente enterradas por ellas que es necesario mucho trabajo con el cuerpo para sacarlas hasta la superficie otra vez y entonces sanarlas mediante la creación teatral. En este sentido, el quehacer escénico de Petrona y las otras compañeras del FOMMA es pedagógico porque parte de observarse a sí mismas para recrear otro ser posible (DIFARNECIO, 2013, p. 97).

Si bien los investigadores y las investigadoras han insinuado, aunque no profundizado, el potencial político y crítico de las representaciones identitarias realizadas por estas mujeres en escena al señalar cómo son atravesadas por 
cuestiones de género, sexualidad y raza; los estudios sostienen una visión reducida a cómo los "usos y costumbres" afectan la vida de estas mujeres sin tomar, en amplia consideración, por ejemplo, el impacto del racismo estructural y el neoliberalismo sobre las comunidades indígenas $y$, específicamente, contra las mujeres indígenas. Las heridas infringidas contra estas mujeres son también producto de las condiciones específicas en que viven muchas comunidades indígenas de la región: crímenes de lesa humanidad, pobreza y alcoholismo, por ejemplo. Asimismo la crítica ha señalado que:

La pertinencia de la propuesta teatral de FOMMA no ha sido lo suficientemente explorada para comprender cómo un teatro hecho por mujeres indígenas de Chiapas aporta a la transformación social y de qué manera la crítica reflexiva creada por medio del cuerpo y la memoria se constituye en una herramienta de denuncia y autodeterminación. (DIFARNECIO, 2013, p. 101)

La labor de estas mujeres por lograr una transformación personal pero también social porque las atraviesa a ellas, sus familias y sus comunidades, se localiza en un contexto mayor de lucha de los pueblos indígenas por obtener derechos y autonomía. En este caso particular, es inevitable la referencia a la lucha encabezada por las mujeres zapatistas, quienes también han denunciado las injusticias cometidas contra ellas en el interior de sus comunidades pero igualmente en el contexto nacional como mujeres y como mujeres pertenecientes a comunidades indígenas. Tanto las mujeres del FOMMA como las zapatistas han señalado en múltiples ocasiones el desprecio que se les tiene y con que se les trata fuera de sus comunidades por cómo visten, hablan, piensan y el color de su piel; pero también dentro de sus comunidades cómo se les niega el derecho a la educación, cómo se les obliga a casarse y, en definitiva, cómo se las mutila del derecho a la autodeterminación sobre sus propias vidas:

[...] los indígenas estamos viviendo apartados, separados de los demás mexicanos [...] Quiero explicarles la situación de la mujer indígena que vivimos en nuestras comunidades [...] hemos venido sufriendo el dolor, el olvido, el desprecio, la marginación y la opresión. [...] no contamos con los servicios de agua potable, luz eléctrica, escuela, vivienda digna, carreteras, clínicas, menos hospitales [...] no nos cuidan bien. [...] piensan que $[\ldots]$ no valemos, no sabemos pensar, ni trabajar, como vivir nuestra vida. [...] no podemos decir nada porque nos dicen que no tenemos derecho de defendernos. [...] nos burlan los ladinos y los ricos por nuestra forma de vestir, de hablar, nuestra lengua, nuestra forma de rezar y de curar y por nuestro color, que somos el color de la tierra que trabajamos. 
[...] Nos dicen que somos cochinas, que no nos bañamos por ser indígena.

[...] No les cuento todo esto para que nos tengan lástima o nos vengan a salvar de esos abusos. Nosotras hemos luchado por cambiar eso y lo seguiremos haciendo. Pero necesitamos que se reconozca nuestra lucha en las leyes [...] Nosotras además de mujeres somos indígenas y así no estamos reconocidas. Nosotras sabemos cuáles son buenos y cuáles son malos los usos y costumbres. (RAMONA, 2001)

En la literatura especializada se ha señalado que a los hombres, pero principalmente a las mujeres indígenas, les ha sido negado hacerse presentes en cuerpo y voz para ocupar un lugar distinto al de la humillación y el desprecio en la comunidad y en la nación mexicana para la cual esos vestidos, esas lenguas y el color de la piel son apreciados sólo cuanto más lejos nos parezcan en el tiempo allá en el origen, en los bordes de la modernidad, de la identidad nacional, la identidad mestiza (UNDERINER, 2010). Justamente esta es la labor que se le reconoce a Petrona y a sus compañeras del FOMMA, el haber dado cuerpo y voz a sus experiencias, sus reflexiones y sus posicionamientos desde el escenario teatral enfrentando la desaprobación de sus propias comunidades y colegas teatristas, quienes consideraban amenazante la ventilación de estos acontecimientos en la esfera pública (UNDERINER, 2010).

El 12 de enero de 2019 se asistió a la presentación de Dulces y Amargos Sueños, un unipersonal escrito, actuado y dirigido por Petrona de la Cruz Cruz en la Galería Muy, centro especializado en arte maya contemporáneo y dirigido por John Burstein W. en San Cristóbal de las Casas, Chiapas. Aunque se tuvo la oportunidad de ver personalmente esta representación, también se consultó frecuentemente la grabación de otra función de la misma obra disponible en YouTube. La experiencia en vivo permitió conocer sobre el lugar de representación y la audiencia específica de esta función, que difiere de la que podemos ver mediante la grabación. El video, en cambio, facilita la recuperación de detalles de la obra que se pudieron haber olvidado al no documentarlos mediante fotografías y notas. De esta manera se ha tomado en cuenta dos funciones de una misma obra que tuvieron lugar en días y espacios disímiles.

La función que vemos en el video, a diferencia de la que se presenció personalmente, tuvo lugar en un teatro tradicional, con iluminación y sonido. Petrona, frente al distanciamiento propiciado por un espacio como éste, sintió la necesidad de interactuar con el público. Ella comenzó esta función 
caminando desde la platea hasta el escenario y en otro momento preguntó directamente a la audiencia: "¿ustedes saben lo que es el metate?". ${ }^{3}$

Por el contrario, la función de Dulces y Amargos Sueños, a la que se asistió, se presentó en un salón para exposiciones de la Galería Muy. Es decir, no tuvo lugar en un escenario teatral tradicional como el que se mencionó anteriormente. No había telón, ni tramoya de luces, ni escenario elevado por encima del nivel del auditorio de butacas convencionales. El espacio de representación estaba delimitado por una pared de fondo, pasto en el suelo y veladoras, así como por los objetos escenográficos necesarios para recrear un espacio doméstico y sacro al mismo tiempo así como para apoyar la acción escénica: un anaquel, dos sillas y otros objetos de uso cotidiano como un mandil, un rebozo, una bolsa, un sombrero y flores.

El público fue acomodado en sillas frente a este espacio escénico, mediando sólo, si acaso, un par de metros entre Petrona y la audiencia conformada por una decena de personas. Esta cercanía durante la representación quizá facilitó el diálogo directo con la creadora al concluir la obra, cuando hubo una ronda de preguntas. En ese momento se comprobó que todo el montaje era autobiográfico y autorreferencial, si bien no es realista sino que el guion dramático responde a las formas de la memoria como la narración y la elipsis temporal. Nos dice Petrona durante la puesta en escena: "recuerdo cómo mi mamá", "recuerdo cómo mi abuelita", "recuerdo cuando iba a la fiesta", "recuerdo que me gustaba".

Petrona nos cuenta cómo se arreglaba para ir a la fiesta, cómo pintaba su cara con papel crepé, también quiénes, de dónde venían y cómo llegaban a la fiesta, algunos en camiones y otros en burros, los que traían fruta: cañas, limas, chicozapotes, guineos morados. La fiesta duraba 3 días en los que cocinaban mucha carne, un alimento que escasea en la comunidad y que se reserva para compartir en momentos de celebración. Petrona, entre chistes y palabras serias, nos relata que a los 9 años se sentía una mujer porque lavaba, planchaba, cocinaba, cuidaba a su mamá, despertaba a las tres de la mañana y hacía las tortillas a las once de la noche cuando regresaba de la fiesta. También nos dice que le gustaba hablar con sus muertos y complacerlos con veladoras para que la visitaran.

Entre estos dulces recuerdos, Petrona nos narra cómo fue secuestrada, violada y embarazada en su juventud por un hombre que su padre conocía; también cómo se ocupó de la educación de su hijo y sus hermanos y hermanas

${ }^{3}$ Nombre de origen náhuatl que designa las piedras de molienda. 
menores cuando murió su madre y cómo su padre ni siquiera les daba de comer, además de que la expulsó a ella de la casa cuando él contrajo matrimonio con su segunda esposa. Petrona recuerda que el mismo árbol de peras que guardaba los ombligos de ella y sus hermanos y hermanas, era el mismo que había sido testigo de las violaciones que uno de sus hermanos cometía contra ella.

Aunque Dulces y Amargos Sueños nos muestra más directamente los abusos físicos, psicológicos y económicos cometidos contra algunas mujeres mayas en sus propios hogares y comunidades a mano de los hombres que las rodean; también podemos recopilar algunos datos sobre los maltratos contra ellas en otros contextos por el sólo hecho de ser eso "mujeres" e "indígenas"; por ejemplo, en el ámbito escolar cuando el maestro las humillaba y las castigaba física y psicológicamente poniéndoles corcholatas en las rodillas o negándoles el tiempo de recreo a ella y a sus compañeras; o en el contexto laboral cuando otras mujeres coletas ${ }^{4} \mathrm{o}$ con una posición económica superior le negaron el pago por su labor a sabiendas de que Petrona no podría acudir a ninguna instancia institucional para reclamar justicia.

Sin embargo, la propia presencia de Petrona en escena, su vestuario, lenguaje y sus dichos - que también nos hacen reír - nos narran mucho más que la brutalidad de estos acontecimientos. Petrona apoya estas narraciones con acciones escénicas y objetos escenográficos. Ella recrea su andar descalzo, de pies rotos, sangrantes y adoloridos por las heladas y mimetiza cómo le curaban las heridas con agua de maravilla, una planta; o cómo elaboraba las tortillas o cómo su madre la enseñaba a moler en el metate. También, aunque la obra es en español, Petrona encarna con su voz la de su "abuelita", una mujer "con los ovarios bien puestos, con un carácter que nadie le aguantaba", y nos habla en tzotzil, su lengua materna, la lengua que hablan la mayoría de las personas adultas mayores de la comunidad, quienes muchas veces no son hablantes de español y, por esto, se les obstaculiza el acceso a la salud, a la educación y a la justicia, por ejemplo.

Así, mediante narraciones y acciones, podemos percibir la cotidianidad en la comunidad. La ambientación del espacio doméstico de la infancia y juventud de Petrona está enfatizada con los tejidos mayas de la región que observamos en su blusa, rebozo y una bolsa. A diferencia de otras mujeres indígenas, Petrona viste un pantalón color marrón. Quizá el uso del pantalón se deba a la

\footnotetext{
${ }^{4}$ Así se llaman a sí mismos los habitantes de San Cristóbal para distinguirse de los diversos pueblos originarios de la región y resaltar su identificación con una ascendencia española.
} 
necesidad de emplear una prenda más cómoda para realizar las diferentes acciones escénicas, aunque ciertamente es un signo que enuncia diferencia con respecto a una norma, un uso, una costumbre y también un estereotipo: la mujer indígena viste siempre falda.

Lo que la obra no narra es el rechazo, el desprecio y la humillación por parte de los familiares, colegas teatristas y compañeros de clase que Petrona también enfrentó. Unos la tildaban de loca y prostituta; los otros, de indígena ignorante analfabeta. Al concluir la presentación de Dulces y Amargos Sueños en la Galería Muy, quienes estábamos presentes tuvimos la oportunidad de escuchar, en voz de Petrona, cómo la desaprobaban en su propia casa y en su comunidad al comenzar a hacer teatro.

Petrona, quien durante su trabajo con Sna Jtz'ibajom, había representado mujeres tratadas como objetos - diríase como medios de (re)producción agrícola, alimentaria y de cuidados - en las que veía reflejadas su propia vida y la de su madre; decidió escribir su primera obra Una Mujer Desesperada. Sin embargo, sus compañeros de Sna Jtz'ibajom se negaron a llevar esta obra a escena porque ventilaba problemas internos de la comunidad que, según ellos, traicionaban el pacto que como indígenas tenían unos con otros. Es entonces cuando Petrona e Isabel salen del grupo y deciden trabajar juntas, con otras mujeres. Hasta la actualidad, ellas han escrito, dirigido y actuado sus propias obras y han encarnado los roles masculinos. A través de las voces de estas mujeres, los hombres de sus comunidades dicen los abusos y daños que han cometido contra ellas.

El objetivo de estas obras fue acceder a una vida digna mediante un trabajo digno, desenterrar los abusos y sacar a la superficie las heridas para sanarlas, pero el alcance fue mucho mayor, la práctica estética performativa de Petrona la ha cambiado a ella y a otras mujeres en un constante quehacer, rehacer, crear, recrear y transformarse a sí mismas en sus hogares, en la comunidad y en el contexto nacional mexicano.

Aunque la historia de Dulces y Amargos Sueños es cruel, no es lastimera, ni busca recrear a una mujer sufrida. Es notable que Petrona representa estas memorias una vez que ha sanado mediante el propio proceso de escritura y montaje de la obra, así como mediante la realización profesional. Aunque, como se mencionó arriba, muchas personas de la comunidad la llamaron prostituta y loca por atreverse a escribir y actuar, más tarde se le dio un reconocimiento por ser la primera mujer indígena actriz y dramaturga.

Lamentablemente, otro aspecto de la relación entre racismo y arte en México ha sido la imposibilidad para los indígenas y especialmente para las mujeres 
indígenas de acceder masivamente a la educación básica, a la educación media superior - Petrona concluyó la primaria a los 17 años - , a la formación artística profesional así como a un público más amplio. Como se ha dicho en más de una ocasión en este documento, con contadas excepciones, son más conocidas a nivel nacional e internacional las obras que representan a los y las indígenas en roles estereotipados como los borrachos y las sirvientas, que las propias producciones artísticas de los y las indígenas. El quehacer artístico de las personas indígenas se difunde principalmente a través del turismo, el folklor, el comercio y la moda nacional. Dulces y Amargos Sueños es una obra autobiográfica escrita, actuada y dirigida por una mujer tzotzil, quien nos narra en primera persona sus memorias. La perspectiva que tenemos sobre los hechos es la de la propia Petrona, quien mediante este proceso creativo ha curado las heridas de tales acontecimientos y roto con el silencio que se le ha impuesto como mujer indígena dentro y fuera de su comunidad.

En Dulces y Amargos Sueños, hay un reconocimiento a la labor de las mujeres indígenas no sólo en sus comunidades sino también en casa de otras mujeres con mejor posición económica para quienes realizan labores domésticas y de cuidados. Sin embargo, mediante la perspectiva de Petrona se enfatiza el valor de esta labor. Es decir, la labor misma no denigra a la mujer indígena por hacerla, no es ella inferior por su trabajo; sino que quien la contrata así la considera de antemano y por ello falta en sus derechos: dar un trato y pago justos.

Dulces y Amargos Sueños nos permite entender la violencia de género desde la perspectiva de una mujer tzotzil y ponerla así en relación con otras formas de la violencia agudizadas por prácticas racistas y clasistas que Petrona reporta a través de su experiencia principalmente fuera de su comunidad: la escuela y las casas donde trabajó como empleada doméstica. Además, Petrona registra esta experiencia en términos de desprecio y humillación, principalmente.

Entonces, por una parte, la práctica estética performativa de Petrona nos pone en contacto con la reflexión en primera persona de una mujer indígena sobre su lugar dentro y fuera de la comunidad; además, esta práctica se presenta como un medio o facilitador para sanar en términos emocionales heridas profundas, pero también para reubicarse como mujer tzotzil tanto en su hogar, como en su comunidad como en el contexto nacional. Cuando Petrona nos cuenta estas crueldades, lo hace desde la mujer nueva que es: profesionista, que exige respeto, justicia y dignidad en el trato hacia ella, educadora, pensadora y creadora. Podemos constatar esta transformación al ver a la propia Petrona escribiendo, dirigiendo y actuando su propia obra. Por 
tanto, Dulces y Amargos Sueños no es sólo una narración de acontecimientos del pasado, sino que podemos ver en el hecho mismo de la representación teatral en un espacio artístico, cómo Petrona se ha reinventado a sí misma, su dolor y su quehacer actual, abriendo con mucha tenacidad un espacio para ella como mujer tzotzil en su hogar, en su comunidad pero también en el panorama teatral y artístico mexicano.

Así Petrona muestra cómo, con gran esfuerzo y a veces poniendo en riesgo la vida misma, logra romper con esta estructura que la condena a ese lugar de objeto y medio de (re)producción. Sin embargo, esto no quiere decir, como señala Petrona en Dulces y Amargos Sueños, que todas las mujeres indígenas tengan la posibilidad real de salir de la situación de pobreza y violencia en la que viven. Entonces la práctica de Petrona trasciende el espacio escénico hacia el pedagógico al crear junto a Isabel el FOMMA, un espacio para verdaderamente facilitar una mejor vida para ellas y otras mujeres mayas en la casa, en la comunidad y en México. En este sentido, podríamos afirmar que tanto la performance como la praxis artística, pedagógica y política de Petrona de la Cruz Cruz produce realidad, una realidad que trasciende el ámbito de la ficción y del arte teatral.

\section{Conclusión}

A lo largo de este documento se ha podido apreciar que el modo en que el racismo se materializa en la realidad social es variable y en relación con otras formas de opresión, violencia y discriminación. Específicamente en México, la ideología racial operativa lo ha sido el mestizaje biocultural. En este país, el derecho ciudadano pasa a través del ideal de un ser mestizo que, en un proceso de asimilación, inevitablemente deberá tender al blanqueamiento racialocultural. El racismo atraviesa la vida política, pública, pero también cotidiana de individuos y colectividades. Para que el racismo se ejerza, la sociedad es clasificada y dividida en razas humanas. Estas razas se inscriben en nuestros cuerpos y nuestras experiencias mediante múltiples marcadores y prácticas culturales en el sentido más amplio. La forma en que se reproduce la vida en la actualidad es especista y racista.

Por otra parte, la lucha antirracista siempre ha sido urgente y se realiza desde diversos ámbitos y mediante incontables vías. En este artículo se ha mostrado cómo las prácticas estéticas antirracistas producen un conocimiento sobre cómo se vive y se reproduce el racismo en la vida cotidiana e institucional; pero también cómo se puede accionar para crear otras 
configuraciones de la realidad, negándose a nutrir los estereotipos de raza, género y clase, convirtiendo experiencias de opresión en experiencias de liberación al cuestionar insistentemente: ¿qué cuerpo?, ¿de quién es el cuerpo?, ¿Cómo se construye el cuerpo?

En este sentido, el campo metodológico que ofrecen los Estudios de Performance procuró las herramientas necesarias para analizar la performance escénica Dulces y como una expresión artística pero también como una praxis performativa, que es importante estudiar porque los propios regímenes de racismo y opresión eliminan, ocultan y silencian los actores y los actos que se alzan en su contra. Por lo mismo, no es en los archivos de las instituciones al servicio del poder-saber hegemónico que vamos a encontrar, en su mayoría, estos actos de rebelión, insubordinación y autodefensa.

En este artículo en particular se vio cómo se entrelazan en la vida cotidiana la opresión de género y raza; y además cómo el Estado nación mexicano provee los recursos simbólicos y materiales para que se ejerza el racismo en relación con una diversidad de opresiones y violencias. En muchos casos en México, la experiencia frente al racismo se expresa en términos de humillación, desprecio y pérdida de la dignidad, todo lo que conduce a un sentimiento donde se niega al propio ser, a sí mismo. Esta negación ya está explícitamente en la ideología del mestizaje, aun cuando este país se ha declarado una nación pluriétnica y multicultural desde 1992. Cada vez más los investigadores y las investigadoras, los artistas y las artistas, los activistas y las activistas eligen poner fin al ideal del ser mexicano mestizo porque niega la existencia de hombres y mujeres indígenas, personas afromexicanas y muchas otras que habitan México o transitan por su territorio.

En este estudio, se vislumbraron otros aspectos que sin duda pueden ser profundizados, por ejemplo, el acceso al pensamiento crítico de las mujeres indígenas que se produce no sólo desde los repertorios, y también la revalorización del pensamiento y las praxis antirracista que se produce desde nuestras experiencias locales. 


\section{Referencias}

AGUIRRE BELTRÁN, Gonzalo.

(1989). La Población Negra de México 15191810. Universidad Veracruzana.

ARISTEGUI NOTICIAS.

(7 de agosto de 2019). Galardonan a Petrona de la Cruz con la Medalla Rosario Castellanos: "Las Plumas de la Serpiente" [Video]. YouTube. Disponible en

https://aristeguinoticias.com/0708/multimed $\mathrm{ia/galardonan-a-petrona-de-la-cruz-con-la-}$ medalla-rosario-castellanos-las-plumas-de-laserpiente-video/. Consultado el 1 de enero de 2019.

DE LA CRUZ, Petrona.

(30 de junio de 1993). Una Mujer Desesperada [Video]. Hemispheric Institute Digital Video Library. Disponible en

http://hidvl.nyu.edu/video/000509489.html. Consultado el 1 de septiembre de 2017.

DE LA CRUZ, Petrona.

(7 de julio de 2003). La Bruja Monja [Video]. Hemispheric Institute Digital Video Library. Disponible en

http://hidvl.nyu.edu/video/003793950.html. Consultado el 1 de septiembre de 2017.

DE LA CRUZ, Petrona.

(14 de marzo de 2005). Soledad y Esperanza [Video]. Hemispheric Institute Digital Video Library. Disponible en

http://hidvl.nyu.edu/video/000557665.html. Consultado el 1 de septiembre de 2017.

DE LA CRUZ, Petrona. y TAYLOR, Diana.

(29 de mayo de 2011). Interview with Petrona de la Cruz Cruz [Video]. Hemispheric Institute Digital Video Library. Disponible en http://hidvl.nyu.edu/video/003756353.html. Consultado el 1 de septiembre de 2017.

DE LA CRUZ, Petrona. [DARINKA RAMIREZ]. (13 de agosto de 2017). Dulces y amargos sueños [Video]. YouTube. Disponible en https://www.youtube.com/watch?v=R7LXYAJB VLY. Consultado el 1 de septiembre de 2017.
BASAVE BENÍTEZ, Agustín.

(2002). México Mestizo. Análisis del nacionalismo mexicano en torno a la mestizofilia de Andrés Molina Enríquez. Fondo de Cultura Económica.

CASTELLANOS, Alicia.

(2000a). Antropología y racismo en México. Desacatos, n. 4, p. 53-79. https://doi.org/10.29340/4.1234

CASTELLANOS, Alicia.

(2000b). Racismo, Multietnicidad y Democracia en AméricaLatina. Nueva Antropología. Revista de Ciencias Sociales, v. XVII, n. 58, p. 9-25. Disponible en http://www.redalyc.org/articulo.oa?id=15905 802. Consultado el 1 de septiembre de 2016.

CHARBELL, Lucio.

(22 de octubre de 2019). Los Papeles de Incultas y Sirvientas no nos Representan: Mujeres Cineastas Indígenas en el FICM 2019. Revolución 3.0. Disponible en https://revolucion.news/los-papelesincultas-sirvientas-no-nos-representanmujeres-cineastas-indigenas-ficm2019/?fbclid=IwAR2 KdKbxw9EIdrCOSzDZUcVg or3qbQSqvaBRBFVyscsMkJuVJY3yZQDAPDI. Consultado el 25 de octubre de 2019.

CONSEJO NACIONAL PARA PREVENIR LA DISCRIMINACIÓN.

(2011, julio). Encuesta Nacional sobre Discriminación en México. ENADIS 2010. Resultados Generales. Disponible en http://www.conapred.org.mx/userfiles/files/ Enadis-2010-RG-Accss-002.pdf. Consultado el 15 de agosto de 2016.

DIFARNECIO, Doris.

(2013). Teatro Popular Criado pelas Mulheres da Fortaleza da Mulher Maya (FOMMA) nos Altos de Chiapas, México. ASPAS, v. 3, n. 1, p. 96-104. 10.11606/issn.2238-3999.v3i1p96-104

GALL, Olivia.

(2016). Interseccionalidad e interdisciplina para entender y combatir el racismo. 
INTERDisciplina, v. 2, n. 4, p. 9-34. http://dx.doi.org/10.22201/ceiich.24485705 e.2014.4

GALL, Olivia.

(2013). Mexican Long-Living Mestizophilia versus a Democracy Open to Diversity. Latin American and Caribbean Ethnic Studies, v. 8, n. 3, p. 280-303.

https://doi.org/10.1080/17442222.2013.797 212

GALL, Olivia.

(2004). Identidad, Exclusión y Racismo: Reflexiones Teóricas y sobre México. Revista Mexicana de Sociología, v. 66, n. 2, p. 221-259. Disponible en

http://www.scielo.org.mx/scielo.php?script=s ci_arttext\&pid=S0188-25032004000200001.

Consultado el 15 de agosto de 2016.

GALL, Olivia.

(2001). Estado Federal y Grupos de Poder Regionales frente al Indigenismo, el Mestizaje y el Discurso Multiculturalista: Pasado y Presente del Racismo en México. Debate Feminista, v. 24, p. 88-115. https://doi.org/10.1080/17442222.2013.797 212

GÓMEZ IZQUIERD0, Jorge, y SÁNCHEZ DÍAZ DE RIVERA, María Eugenia.

(2012). La ideología mestizante, el guadalupanismo y sus repercusiones sociales:una revisión crítica de la "identidad nacional". (2a ed.). Universidad Iberoamericana Puebla, Benemérita Universidad Autónoma de Puebla,Instituto de Ciencias Sociales y Humanidades "Alfonso Vélez Pliego".

INE.

(2021, 16 enero). Establece INE acciones afirmativas para la participación de grupos vulnerables en elecciones 2021. Central Electoral. Disponible en https://centralelectoral.ine.mx/2021/01/15/ establece-ine-acciones-afirmativas-para-laparticipacion-de-grupos-vulnerables-enelecciones-2021/. Consultado el 31 de enero de 2021.
LÓPEZ BELTRÁN, Carlos.

(2014). La matriz de lo hereditario. Raza, genética e identidad mestiza. INTERdisciplina, v. 2, n. 4, p. 63-73. https://doi.org/10.22201/ceiich.24485705e. 2014.4.47206

LÓPEZ BELTRÁN, Carlos.

(2001). Para una crítica de la noción de raza. Ciencias, n. 60, p. 98-106. Disponible en https://www.revistacienciasunam.com/es/95revistas/revista-ciencias-60/808-para-unacritica-de-la-nocion-de-raza.html. Consultado el 1 de septiembre de 2016.

LOZANO, Rafael.

(27 de agosto de 2019). Lukas Avendaño: Un caso exitoso del fracaso. Disponible en https://www.quepasaoaxaca.com/es/lukasavendano-un-caso-exitoso-del-fracaso/. Consultado el 1 de diciembre de 2019.

MORENO FIGUEROA, Mónica.

(2016). El archivo del estudio del racismo en México. Desacatos, n. 51, p. 92-107. Disponible en http://www.scielo.org.mx/pdf/desacatos/n51 /2448-5144-desacatos-51-00092.pdf.

Consultado el 1 de diciembre de 2016.

OEHMICHEN BAZÁN, Cristina.

(2006). Aspects de la Violence dans les Relations Interethniques et le Racisme à Mexico.

ORTEGA PONCE, Liudmila.

(diciembre de 2012). Las Relaciones de Género entre la Población Rural del Ecuador, Guatemala y México. Comisión Económica para América Latina. Disponible en https://repositorio.cepal.org/bitstream/hand le/11362/5848/1/S1200873_es.pdf.

Consultado el 1 de febrero de 2019.

RAMONA, Comandanta.

(2001). Discurso de la Comandanta Esther en la Tribuna del Congreso de la Unión. Presentado en el Congreso de la Unión, México. Enlace Zapatista. Disponible en https://enlacezapatista.ezln.org.mx/2001/03 /28/discurso-de-la-comandanta-esther-en-latribuna-del-congreso-de-la-union/. Consultado el 31 de agosto de 2016. 
RIVERA CUSICANQUI, Silvia.

(2015). Sociología de la imagen: miradas Ch'ixi desde la historia andina. Tinta Limón.

RIVERA CUSICANQUI, Silvia.

(2010). Ch 'ixinakax-Utxiwa: una reflexión sobre prácticas y discursos descolonizadores. Tinta Limón. Disponible en https://issuu.com/educacionintercultural/doc s/chixinakax-utxiwa. Consultado el 1 de diciembre de 2018.

RUIZ, Apen.

(2001). La india bonita: nación, raza y género en el México revolucionario. Debate Feminista, v. 24, p. 142-162. Disponible en https://www.jstor.org/stable/42625405. Consultado el 1 de febrero de 2019.

SECRETARÍA DE GOBERNACIÓN.

(2020, enero). Informe sobre fosas clandestinas y registro nacional de personas desaparecidas o no localizadas. Disponible en https://www.gob.mx/cms/uploads/attachme nt/file/535387/CNB_6_enero_2020_conferen cia_prensa.pdf.pdf. Consultado el 1 de marzo de 2020.

SEGATO, Rita.

(2010). Los cauces profundos de la raza latinoamericana: una relectura del mestizaje. Crítica y Emancipación, p. 11-44. Disponible en http://biblioteca.clacso.edu.ar/ojs/index.php /critica/article/view/166. Consultado el 1 de febrero de 2019.

TAYLOR, Diana.

(2003). The Archive and the Repertoire: Performing Cultural Memory in the Americas. Duke University Press.
UNDERINER, Tamara.

(2010). The Demons Nun: FOMMA and the Embodied Politics of Gendered Visibility in Mayan Mexico. Theatre Research International, v. $35, \quad$ n. 2, p. 178-182. https://doi.org/10.1017/S030788331000009 $x$

VELÁZQUEZ GUTIÉRREZ, María Elisa.

(2016). Balances y retos de los estudios antropológicos sobre poblaciones afrodescendientes en México. Anales de Antropología, v. 50, n. 2, p. 177-187. https://doi.org/10.1016/j.antro.2016.05.007

VIVANCO, Adriana.

(18 de noviembre de 2014). Dramaturga y activista chiapaneca "Gracias al teatro ahora soy otra": Petrona de la Cruz. Disponible en https://www.uv.mx/universo/reportaje/graci as-al-teatro-ahora-soy-otra-petrona-de-lacruz/. Consultado el 1 de enero de 2019.

WADE, Peter.

(2005). Rethinking Mestizaje: Ideology and Lived Experience. Journal of Latin American Studies, v. 37, n. 2, p. 239-257. https://doi.org/10.1017/s0022216×0500899 0

\section{Recebido em}

julho de 2021

\section{Aprovado em}

outubro de 2021 